NBSIR $77 \cdot 856$

DO NOT REMOVS:

\title{
PROPOSED STANDARDS \\ FOR LADAR SIGNATURES
}

B. L. Danielson

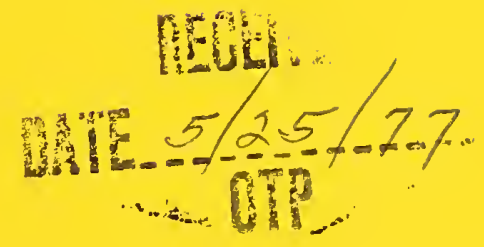

Electromagnetics Division

Institute for Basic Standards

National Bureau of Standards

Boulder, Colorado 80302

April 1977

Prepared for

Ballistic Missile Defense Advanced

Technology Center

P.0. Box 1500

Huntsville, Alabama 35807 



\section{NBSIR 77.856}

\section{PROPOSED STANDARDS FOR LADAR SIGNATURES}

B. L. Danielson

Electromagnetics Division

Institute for Basic Standards

National Bureau of Standards

Boulder, Colorado 80302

April 1977

\section{Prepared for}

Ballistic Missile Defense Advanced

\section{Technology Center}

P. 0. Box 1500

Huntsville, Alabama 35807

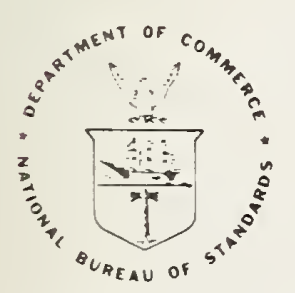

U.S. DEPARTMENT OF COMMERCE, Juanita M. Kreps, Secretary

Dr. Betsy Ancker-Johnson, Assistant Secretary for Science and Technology 


$$
\text { . }
$$


INTRODUCT ION- -

2. UNITS AND RADIOMETRIC NOTATION-_-

3. PROPOSED DEFINITIONS-----

3.1 Reflectance Nomenclature---

a. Bidirectional Reflectance------------------------- 4

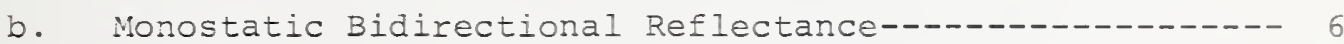

c. Bidirectional Reflectance Distribution Function-------- 6

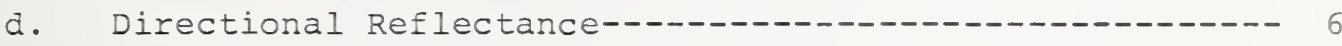

e. Directional Hemispherical Reflectance---------------- 7

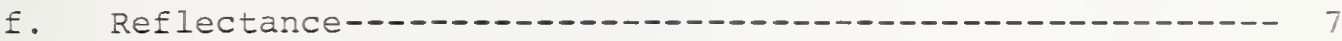

g. Other Terms in Reflectometry--

3.2 Radar Cross Sections----------------------------- 8

3.3 Laser Radar Cross Sections--------------------------- 9

a. Discussion-_-

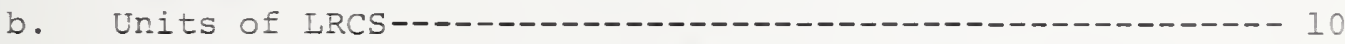

c. Polarization of Ladar Transmitter and Receiver--------- 10

d. Assumptions and Conditions Applying to LRCS Definitions 10

e. Laser Radar Cross Section Definitions---..--.-.-.--- 11

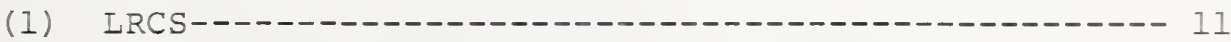

(2) Copolarized LRCS--------

(3) Cross-polarized LRCS------

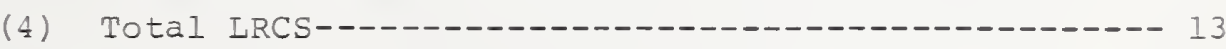

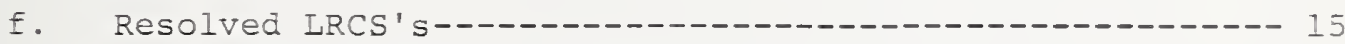

(1) Range-resolved LRCS-----

(2) Doppler-resolved LRCS-------------------- 15

(3) Listributed LRCS---------------------------- Ij

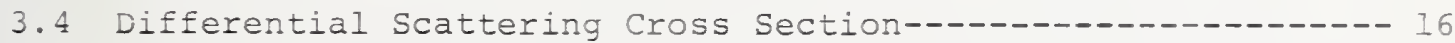

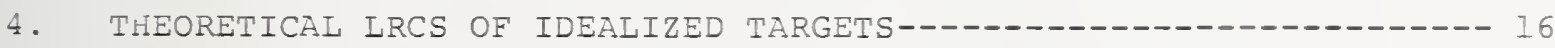

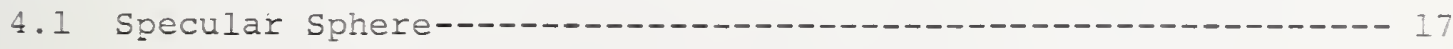

4.2 Lambertian Diffusers--.-.-.

5. LABORATORY CALIBRATION STANDARDS-

5.1 Discussicn---------

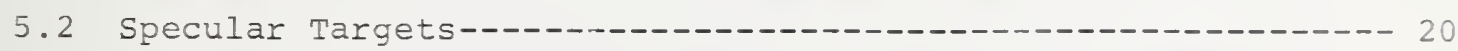

5.3 Diffuse Targets------_-

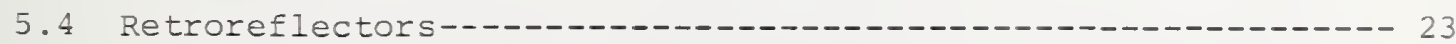

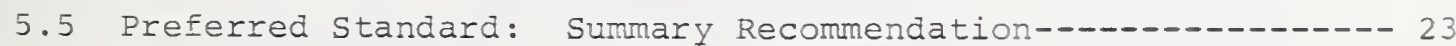

6. CONCLUSIONS-----------

7. REFERENCES----

8. APPENDIX. RADIOMETRIC SYSTEMS-- 
Table I. Symbols and Units-_-

Table II. Monostatic LRCS of Some Idealized Standard Targets----- 19

Table A-1. Former American Standard Nomenclature for Radiometry

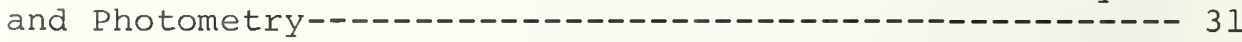

Table A-II. American National standard Nomenclature Illuminating Engineering------------- 32

Table A-III. Proposed Terms and Symbols for Radiometry---_---_---- 33

LIST OF FIGURES

$\underline{\text { Page }}$

Figure 1 .

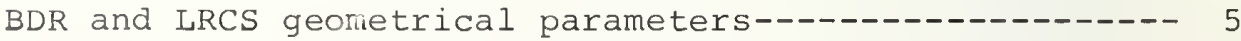

Figure 2.

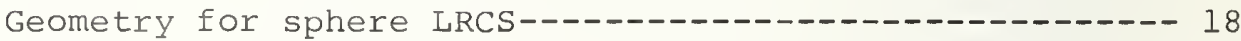

Figure 3 .

Mirror target dimensions--------------------------- 21

\section{ACRONYMS}

$\begin{array}{ll}\text { ASTM } & \text { American Society for Testing and Materials } \\ \text { BDR } & \text { bidirectional reflectance } \\ \text { BRDF } & \text { bidirectional reflectance distribution function } \\ \text { BMDATC } & \text { Ballistic Missile Defense Advanced Technology Center } \\ \text { DRCS } & \text { Doppler resolved cross section } \\ \text { ERIM } & \text { Environmental Research Institute of Michigan } \\ \text { GRC } & \text { General Research Corporation } \\ \text { Ladar } & \text { laser radar } \\ \text { LOS } & \text { line of sight } \\ \text { LR } & \text { laser radar (ladar) } \\ \text { LRCS } & \text { laser radar cross section } \\ \text { MDAC } & \text { McDonnell Douglas Astronautics Company } \\ \text { M.COM } & \text { U.S. Army Missile Command } \\ \text { NBS } & \text { National Bureau of Standards } \\ \text { RV } & \text { reentry vehicle } \\ \text { RRCS } & \text { range resolved cross section } \\ \text { VH } & \text { vertical-horizontal polarization } \\ \text { VLOS } & \text { vector line of sight } \\ \text { VV } & \text { vertical-vertical polarization } \\ & \end{array}$




\section{B.L. Danielson}

\section{ABSTRACT}

Tnis report attempts to assist in providing a common basis for the reporting and intercomparison of laser radar cross section (LRCS) data generated at different laboratories for the Ballistic Missile Defense Advanced Technology Center (BMDATC) laser radar signatures program. We are concerned here with recommending preferred definitions of some of the most commonIy used LRCS terms and recomending a calibration target standard.

Key words: Laser radar; laser radar signatures; target standards.

\section{INTRODUCTION}

'he laser radar (LR) signatures program sponsored by the Ballistic -issile Defense Advanced Technology Center is directed towards employing LR carget scattering for the identification and discrimination of threatening oojects. The scattered target radiation is usually expressed in terms of various types of laser radar cross sections (LRCS). Unfortunately, in the jast there nas not been universal agreement on the precise definitions of cne LRCS's of interest, nor has there been a common traceable method for calibrating the diverse systems used in measuring experimental values of LRCS's [1].* For example, cross section definitions based on radar use can wiffer oy a factor of 4 from definitions based on the optical use of uiffuse plates [2]. Polarization is another factor that is not consistently taken into account.

Tnis report represents an effort by the National Bureau of Standards (ivBS) to encourage the adoption of a common basis for LRCS measurements. Tne major thrust of this initial effort assumes two forms. We propose stanciari definitions of various terms employed in connection with LR signatures (section 3), and we propose that all laboratory LRCS measurements be ultimately referenced to a preferred type of calibration standard (section כ.ग). The more important recommendations in the body of the text follow the neading "Summary Recommendation."

It was our intention in the present work to base our recommendations as inucn as possible on current usage, so that adoption of these proposals woulu cause a minimum disruption in format reporting. To provide the necessary background, we conducted a survey of the appropriate literature, some of which is included in the references. Discussions were neld witn representatives of the major BMDATC contractors. Finally, a written questionnaire was sent to these contractors to determine their ॠFigures in brackets indicate the literature references at the end of this paper. 
preferences on definitions and standards. Some substantive differences of opinion became evident during the course of this study. Nevertheless, we feel that our present conclusions represent a reasonable consensus on present usage, along with some subjective opinions of our own. One of these subjective considerations was that current LR terminology should, wherever possible, be compatible with corresponding quantities used in the radar field. Another conclusion was our recommendation that the specular sphere (or mirror) should be the preferred standard calibration target for cross section measurements and that the cross section of diffuse secondary standard targets should be determined by measurements relative to this specular sphere (or mirror).

\section{UNITS AND RADIOMETRIC NOTATION}

The système International d'Unitès (International System of Units) with the abbreviation SI is the modernized metric system which represents the offically recognized basis of measurement adopted by NBS, The American Society of Testing Materials (ASTM), and many international standards laboratories. It is the policy of NBS to encourage its universal acceptance. We also feel that it is desirable to have all reported measurement data ultimately traceable to the base SI units. These units, symbols, and conversion factors are detailed in many accessible publications [3-7].

While there are no serious alternatives to the use of SI units, there is still no universally accepted system of symbols and definitions for radiometry. In this report we will use the American National Standard Nomenclature, although this should be considered only our own preference. It has also been adopted for mandatory use by the Department of Defense [63]. This system is discussed in a review article by Mayer-Arendt [8], a tutorial review by Nicodemus [9], and in table A-II in the present Appendix. A summary of the terms, symbols, and units used in this report is given in table 1. The nomenclature of radiometry and reflectometry is still in a state of flux, and the interested reader will find many further articles in the literature on these subjects $[10-17,78,79]$. The three main radiometric systems are compared in the Appendix.

We will note in passing that there are several common sources of confusion in the area of radiometry. The first concerns the use of the term "intensity." Many standard texts, for example Born and Wolf [18], identify "intensity" with power per unit area $\left(\mathrm{W} / \mathrm{m}^{2}\right)$. In radiometric notation "intensity" refers to power per unit solid angle (W/sr), and is usually restricted to a point source. ${ }^{1}$ Here we will always refer to this latter

${ }^{1}$ Nicodemus has suggested the use of "pointance" in place of "intensity" to avoid this confusion $[78,79]$. 


\section{Quantity}

Raciant energy

Radiant Elux density

Radiant power (radiant Elux)

Radiant intensity

Radiance

Photon intensity

Irradiance ö́ a suriace

Photon flux density

Spectral irradiance

Solid angle

Projected solid angle

Bicirectional reflectance

jirectional reflectance

ReIlectance

Range (distance from target

to receiver)

Racius at curvature of spinere

Segment of sphere (cross section diameter)

LRCS

Intercepted area (or

effective projected area)

Copolarized LRCS

Cross-polarized LRCS

Iotal LRCS

Cross section per unit

projected area

Aspect angle

Bistatic angle

Detector aperture
Symbol

Q joule

W watt/meter ${ }^{2}$

$\risingdotseq$ watt

I watt/steradian

I watt/(zeter ${ }^{2}$.steradian)

Ip quanta/(sec.steradian)

P watc/meter ${ }^{2}$

Wqunta/ $\left(\sec \cdot m^{2}\right)$

E ratt/(meter ${ }^{2}$ nanometer)

- steracian

steradian

' steradian ${ }^{-1}$

D dinensionless

- dimensionless

R meter

a meter

D neter

meter ${ }^{2}$

$\tau_{E}$ meter ${ }^{2}$

$\tau_{11}$ meter ${ }^{2}$

$\sigma_{\perp}$ meter 2

$\sigma_{\text {I }}$ meter

dimensionless

$\checkmark$ radian

\& radian

A meter 2
II

m

rad

rad

Aboreviazica

of tnit

j

$A \cdot m^{-2}$

is

is.sr ${ }^{-1}$

$n \cdot m^{-2} \cdot s r^{-1}$

$\mathrm{c} \cdot \sec ^{-1} \cdot \mathrm{sr}^{-1}$

$\therefore \cdot \pi^{-2}$

$q \cdot \sec ^{-1} \cdot=^{-2}$

$n \cdot m^{-2} \cdot n-1$

sr

sr

$s r^{-1}$

m

$\pi^{2}$

$\pi^{2}$

$-2$

$\pi^{2}$

$m^{2}$

$m^{2}$ 
quantity as "radiant intensity" denoted with the symbol I. Another source of confusion concerns the use of "projected solid angle" denoted here by $\Omega$ (as suggested by Nicodemus [14]), and "solid angle" denoted by w. Both have units of steradians, but differ in the cosine of an aspect angle. Reference [9], for example, elaborates on their distinction which is of importance in the definition and application of radiance and bidirectional reflectance (BDR). A third common source of confusion originates in the similarity of the symbol $\rho$ (for reflectivity) and $\rho^{\prime}$ (for BDR). These, as defined in the next section, are quite different quantities with different dimensions.

\section{PROPOSED DEFINITIONS}

\subsection{Reflectance Nomenclature}

This section discusses the terms and quantities employed in the LR signatures program which we feel need some kind of standard definition. Not all of these are controversial, but they are listed here for completeness. Reflectance and radiometric quantities are important in the experimental determination and theoretical prediction of cross section values, and these will be reviewed first.

\section{a. Bidirectional Reflectance}

The BDR of a surface, denoted by $\rho^{\prime}$, completely specifies its reflectance characteristics. In general it is a function of wavelength, and polarization and orientation of both incident and reflected radiations. The appropriate geometrical configuration for its description relative to LR scattering is shown in figure 1. This figure, as well as our general approach to the description of BDR, has been adapted from reference [20]. We define $B D R$ as the ratio of the radiance $L_{Y}^{r}\left(\theta_{r}, \phi_{r}\right)\left(W / m^{2} \cdot s r\right)$ reflected by the sample in the direction of the receiver $\theta_{r}, \phi_{r}$ with polarization state $y$, to the irradiance $\mathrm{E}_{\mathrm{X}}^{i}\left(\theta_{i}, \phi_{i}\right)\left(\mathrm{W} / \mathrm{m}^{2}\right)$ incident on the target from the direction $\theta_{i}, \phi_{i}$ with polarization state $x$. To be consistent wi.th our LRCS definitions later on, we have taken $\mathrm{E}_{\mathrm{x}}^{i}\left(\theta_{i}, \phi_{i}\right)$ to be the irradiance of the target surface and $w_{x}^{i}\left(\theta_{i}, \phi_{i}\right)$ to be the radiant flux density $\left(W / m^{2}\right)$ in the well-collimated incident laser beam, so that $\mathrm{E}_{\mathrm{x}}^{i}\left(\theta_{i}, \phi_{i}\right)=w_{\mathrm{x}}^{i}\left(\theta_{i}, \phi_{i}\right) \cos \theta_{i}$. The BDR for a given wavelength can then be expressed as

$$
\rho_{X, Y}^{\prime}\left(\theta_{i}, \phi_{i} ; \theta_{r}, \phi_{r}\right)=\frac{L_{Y}^{r}\left(\theta_{r}, \phi_{r}\right)}{E_{x}^{i}\left(\theta_{i}, \phi_{i}\right)} \frac{\text { reflected } W /\left(m^{2} \cdot s r\right)}{\text { incident } W / m^{2}}
$$

and has the dimensions $\mathrm{sr}^{-1}$. The reflected polarization state vector $y$ and incident polarization state vector $x$ need to be specified relative to target geometry in order for $\rho^{\prime}$ to have a unique value. In special cases the 

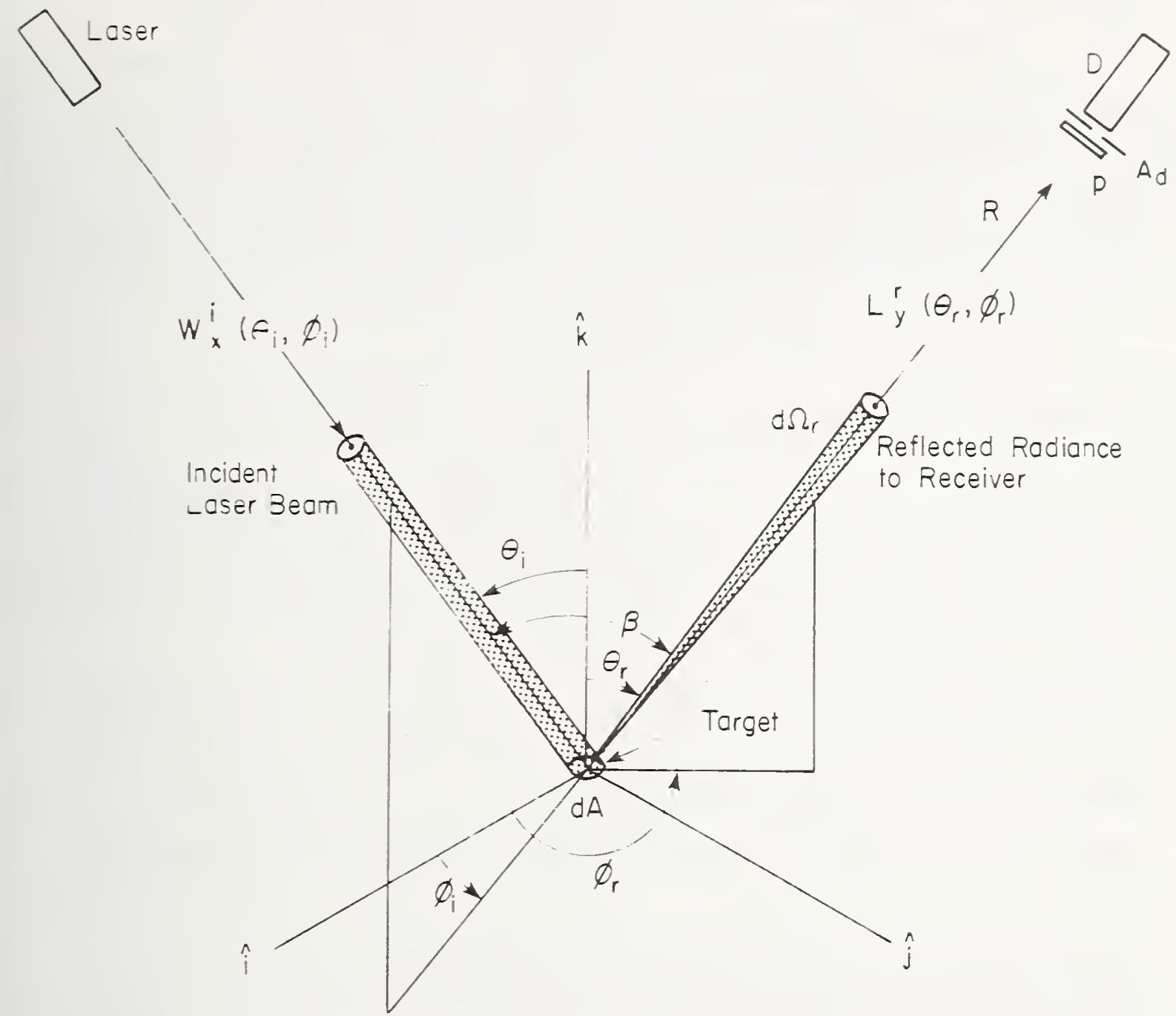

$\mathrm{L}_{\mathrm{y}}^{\mathrm{r}}$ Radiance $\left(\mathrm{W} / \mathrm{m}^{2}-\mathrm{sr}\right)$ with polarization state y reflected from target

$E_{\mathrm{x}}^{i}$ Irradiance $\left(\mathrm{W} / \mathrm{m}^{2}\right)$ of target with polarization state $\mathrm{x}$

$\mathrm{W}_{\mathrm{x}}^{\mathrm{i}}$ Radiant flux density $\left(\mathrm{W} / \mathrm{m}^{2}\right)$ with polarization state $\mathrm{x}$ of laser beam

$\mathrm{W}_{\mathrm{y}}^{\mathrm{T}} \operatorname{Radiant}$ flux density $\left(\mathrm{W} / \mathrm{m}^{2}\right)$ with polarization state $\mathrm{y}$ at detector

entrance pupil

R Range (m)

3 Bistatic angle

D Detector

P Polarizer

A Detector entrance pupil $\left(\mathrm{m}^{2}\right)$

$k$ Surface normal

Figure 1. BDR and LRCS geometrical parameters. The azimuth reference ( $\hat{i}$ axis) is arbitrary. The polar angles are denoted by $\theta$ and the azimuth angles by $\phi$. 
polarization subscripts $\mathrm{x}$ and $\mathrm{y}$ can be written as perpendicular ( $\downarrow$ ) or parallel (II) depending on the direction of the electric field vector relative to the plane of incidence or reflection. If the detector is insensitive to polarization, i.e. senses the sum of the two polarizations, then the appropriate reflection polarization subscript y is denoted by "total" (T). For example, the symbol $\rho^{\prime}, T$ refers to conditions of parallel incident irradiance and a detector that has no polarization preference. By. definition the following relationships exsit between BDR polarization states:

$$
\begin{aligned}
& \rho_{\perp, T}^{\prime}=\rho_{\perp, 1}^{1}+\rho_{\perp, 11}^{1} \mathrm{sr}^{-1} \\
& \rho_{11, T}^{\prime}=\rho_{11,11}+\rho_{11,1} \mathrm{sr}^{-1}
\end{aligned}
$$

Since for diffuse targets $\rho^{\prime}$ and LRCS are proportional, the notation used here can be carried over directly to cross section definitions. Usually BDR refers to a diffusing surface, although the reflected radiance of a specular surface can be calculated using special forms of $\rho^{\prime}[14,15]$.

Summary Recommendation: Preferred definitions and notation for BDR are given by the Willow Run (now ERIM) reports [e.g. 20].

b. Monostatic Bidirectional Reflectance

This is the term used in the case where both incident and reflected directions are the same $\left(\theta_{i}=\theta_{r}, \phi_{i}=\phi_{r}\right.$ and $\left.\beta \equiv 0\right)$, i.e. backscatter case.

\section{c. Bidirectional Reflectance Distribution Function}

This is the term employed by Nicodemus [14], denoted by $\mathrm{f}_{r}$, and defined by the relation

$$
\mathrm{f}_{r}\left(\theta_{i}, \phi_{i}\right)=\frac{d L^{r}\left(\theta_{r}, \phi_{r}\right)}{d E^{i}\left(\theta_{i}, \phi_{i}\right)} \quad\left(s^{-1}\right)
$$

where $\mathrm{dE}^{i}\left(\theta_{i}, \phi_{i}\right)=L^{i}\left(\theta_{i}, \phi_{i}\right) \cos \theta_{i} \mathrm{~d} \omega_{i}$ and $L^{i}\left(\theta_{i}, \phi_{i}\right)$ is the radiance impinging on an element of surface. Our eq. (1) is an adaptation of this concept.

\section{d. Directional Reflectance}

This term is denoted by $\rho_{D}\left(\theta_{i}, \phi_{i}\right)$ for a given wavelength. Its accepted definition is the BDR averaged over the reflectance angles $\left(\theta_{r}, \phi_{r}\right)$. It is usually employed in the case where the incident radiation is unpolarized [20]. Analytically it is defined as the ratio of the power reflected into 
the entire hemisphere to the unpolarized power incident on the sample, or

$$
\rho_{D}\left(\theta_{i}, \phi_{i}\right)=\int_{2 \pi} \rho_{u, T}^{\prime}\left(\theta_{i}, \phi_{i} ; \theta_{r}, \phi_{r}\right) \cos \theta_{r} d \omega_{r}
$$

where $w$ is the reflected solid angle. Since we integrate over this solid angle, $\rho_{D}$ is a dimensionless quantity. For a lossless diffuse surface (see section 4.2 ) the value of $\rho_{D}$ is 1 .

There is another use of the term "directional reflectance" which is used occasionally [68]. This quantity is denoted by $\rho$ " and is defined as

$$
\rho^{\prime \prime}=\rho^{\prime} \cos \theta_{r}
$$

The use of $\rho "$ and "directional reflectance" in this context is discouraged.

\section{e. Directional Hemispherical Reflectance}

This is the term denoted by $\rho\left(\theta_{i}, \phi_{i} ; 2 \pi\right)$ which has been suggested by Nicodemus [14] to replace "directional reflectance" or $p_{D}$. The definition is identical.

\section{f. Reflectance}

The reflectance is the ratio of the reflected radiant flux $\phi_{r}$ to the incident radiant flux $\phi_{i}$

$$
\rho=\frac{\phi_{r}}{\phi_{i}}
$$

and is dimensionless. The reflectance should not be confused with BDR which is a different quantity with different dimensions. Reflectance is sometimes expressed as the sum of the regular (specular) reflectance $\rho_{r}$ and the diffuse reflectance $\rho_{\mathrm{d}}$.

$$
\rho=\rho_{r}+\rho_{d}
$$

It should be noted that "specular" is only meaningful in terms of geometry, specifically when $\theta_{r}=\theta_{i}$ and $\phi_{r}=\theta_{i} \pm \pi$ or when the surface normal bisects the bistatic angle $\beta$. The value of $\rho$ is one for a non-absorbing surface.

\section{Other Terms in Reflectometry}

For more details on the above definitions and others in the field of reflectance and radiometry, the reader is referred to the comprehensive report of Nicodemus [19]. 
Much of the work done with determination of LRCS's is based on earlier, and similar, work in the field of radar. The radar cross section definition, we feel, should also be directly applicable to LRCS measurements. However, we recognize that there is more than a wavelength difference between laser and radar systems (there are no radar gaussian beams, optical receivers are not normally polarization sensitive, etc.). The particular requirements of ladar applications may require some distinctions in definitions. As defined below, however, the LRCS and RCS will usually be equivalent.

Because of its importance, the RCS will be reviewed here. The original RCS [21] was defined so that the only radiation considered at the receiver was the component polarized parallel to the plane wave field incident on the scatterer. This convention is still widely used [22]. Some other standard references, however, do not make this distinction as to polarization [23,27], implying that the total scattered signal (both linear polarizations) is considered in defining the cross section. Since specular targets depolarize the incident radiation only slightly, if at all, there often is no practical difficulty associated with this polarization question. With diffuse surfaces, whose roughness is large compared to a wavelength, the distinction is very important. The RCS is defined as the area intercepting that amount of power which, when scattered isotropically, produces a scattered radiance equal to that observed from the target. The bistatic $\underline{\text { RCS }}$ given by Blacksmith [22] is, for a given wavelength, given by

$$
\sigma\left(\theta_{i}, \phi_{i} ; \theta_{r}, \phi_{r}\right)=\lim _{R \rightarrow \infty} 4 \pi R^{2} \frac{W^{r}\left(\theta_{r}, \phi_{r}\right)}{W^{i}\left(\theta_{i}, \phi_{i}\right)} \mathrm{m}^{2}
$$

using the symbols of table I and figure 1 . We assume that $W^{r}$ and $W^{i}$ are both plane polarized relative to an appropriate coordinate system [22]. Our symbol $W$, as usual, refers to radiant flux density $\left(\mathrm{W} / \mathrm{m}^{2}\right)$. The reflected radiant flux density, referred to the receiver entrance pupil, is denoted by $W^{\Gamma}\left(\theta_{r}, \phi_{r}\right)$. This quantity often is expressed in terms of the reflected intensity $(W / s r) ; I^{r}\left(\theta_{r}, \phi_{r}\right)=R^{2} W^{r}\left(\theta_{r}, \phi_{r}\right)$.

The monostatic $\underline{\text { RCS }}$ is defined for the backscatter case: $\theta_{i}=\theta_{r}$ and $\phi_{i}=\phi_{r} \cdot$

The scattering cross section, as given by Blacksmith [22], is identical to the RCS of eq. (6) with the exception that $W^{r}\left(\theta_{r}, \phi_{r}\right)$ now represents the total reflected (scattered) radiant flux density regardless of polarization, i.e. it is the RCS determined using an unpolarized receiver. In the terminology of the next section, the scattering cross section is equivalent to "total RCS." 
a. Discussion

The generally accepted approach to quantitatively describing the signature or characteristic ladar return from a particular target is in terms of various laser radar cross sections. It would be desirable for the purposes of analysis if the LRCS of a target could have a single numerical value which is a function of the static and dynamic properties of the target (size, shape, composition, spin rate, etc.) in addition to clearly identifiable properties of the beam (wavelength, polarization). This is rarely the case for complex targets under operational conditions. The quantity identified as the LRCS can be affected by range (near-field or far-field), size of the ladar beam relative to the target, beam profile and curvature, coherence, and other effects which enormously complicate the interpretation of the return signal. In particular, the simple quantities we have identified as LRCS data may not be adequate to characterize the target completely. Although other conditions are very important in practical cases, we will emphasize here only the experimental definitions of LRCS made under specific and very specialized environmental conditions. These will be discussed in section $3.3 . d$.

As discussed by Wyman [2], the LRCS is sometimes referenced to the geometrical projected area of a diffusing plate, or diffuse standard. Under this convention a LRCS is equal to the area of a lossless Lambertian surface which produces the same amount of scattered power at the receiver as does the target. This approach gives different LRCS values than our recommended definitions (section 3.3.e) which are more conveniently referenced to a specular sphere, as is the RCS definition mentioned above. However, as long as the cross section is defined in terms of scattered radiant flux density at the detector, rather than an equivalent projected surface area of any standard target, it really is immaterial which standard target is used, and this is the approach we will take in the following LRCS definitions.

Strictly speaking it is not correct to associate the LRCS of a specular spnere $\left(\sigma=\pi a^{2}\right)$ with the "effective" or "interception area" $\sigma_{E}$ which removes an amount of power $E^{i} \sigma_{E}$ from the incident beam and scatters it isotropically. This "interception area" for a sphere is $\sigma_{E}=2 \pi \mathrm{a}^{2}$. This "extra" factor of two is necessary to account for the forward scattering, and is of some nistorical interest. It is discussed in standard texts on scattering theory $[24,25,26]$. This is really of no significance as long as the LRCS is defined analytically in terms of scattered radiant flux density, as it is below. We point this out only as an illustration of another difficulty which can arise when cross sections are referenced to "interception areas" of standard targets. 
Laser radar cross sections have the dimensions of area, with a few exceptions to be mentioned later. The accepted unit is the square meter $\left(\mathrm{m}^{2}\right)$, or decibels above one square meter (dbsm). Theoretical data are sometimes expressed relative to a square wavelength, but this practice is discouraged.

\section{c. Polarization of Ladar Transmitter and Receiver}

The LRCS depends on the polarization of the radiation impinging on the target, and the polarization selector associated with the detector (figure 2). This implies that cross sections are really tensor quantities, or, alternatively, must be expressed in terms of a scattering matrix [27]. We will not consider this approach here, but will only point out that if LRCS's are to be meaningful, the polarization details of both transmitted and detected radiation fields must be completely specified. We will emphasize this consideration in the definitions to follow. Polarization is often stated in terms of the transmitter-receiver-target coordinate system [28], e.g. linear polarization parallel or perpendicular to the plane containing the transmitter, target, and receiver. For LR signature purposes, it is usually better if the polarizations are specified in terms of the symmetry coordinates of the target [29]. This implies that two coordinate systems are required; one to describe the scattering properties of the target and another to define the orientation of the target relative to the laser transmitterreceiver reference frame.

In early radar systems the receiver used the same antenna that served for the transmitter. Under these conditions the receiver only responds to the backscatter which is parallel to the transmitted radiation. It was natural then that the "RCS" should be interpreted as "copolarized RCS." On the other hand, optical detectors are not intrinsically polarization sensitive. (This does not apply, of course, to heterodyne systems or cases where a polarizer is introduced in front of the detector.) For targets that depolarize the impinging radiation, this brings up the question as to whether the LRCS definition should be based on the copolarized return radiation, or on the total (copolarized and cross-polarized) return. This is discussed in sections $3.3 . d$ and $3.3 . e$.

\section{a. Assumptions and Conditions Applying to LRCS Definitions}

In order to simplify our treatment of the LRCS definitions, we will impose a number of conditions which will considerably restrict the scope of their applicability, but hopefully this will help clarify the issues involved. 
The somewhat idealized situation to be considered is illustrated in figure 1. We will assume that the following experimental conditions are met (with certain exceptions to be considered later):

(1) Plane waves impinge on the target, and these plane waves have a constant phase and amplitude over the dimensions of the target.

(2) The detector is in the far-field of the target, i.e. $\mathrm{R}>\frac{2 \mathrm{~L}^{2}}{\lambda}$ where $L$ is the maximum dimension of the target; also the detector area $A_{d}$ is such that $R>\frac{2 A_{d}}{\lambda}$. This assures that the effective area of the detector is small compared with the corresponding Airy disc of the target, and also implies that the target is smaller than the detector field of view.

(3) For diffuse targets, an average is taken over many speckles.

(4) The geometrical optics limit applies; $\lambda \ll<$.

(5) The laser is quasi-cw (long pulse approximation).

(6) The laser beam size is much greater than $L$ at the target (flood illumination).

(7) The laser transmitter is plane polarized.

In many practical cases of interest these conditions can be relaxed and meaningful measurements still obtained. There are situations, however, where LRCS values may be drastically altered if these conditions are not met. A later report in the present series will attempt to expand on this subject. With the above enumerated assumptions, we can now make our recommended LRCS definitions.

e. Laser Radar Cross Section Definitions

(1) LRCS -- We feel that the basis of the LRCS definition should be consistent with and have the same origin as the RCS described above. From the phenomenological point of view, the LRCS may be similarly defined as the area intercepting sufficient power out of the transmitted ladar beam to produce the given echo by isotropic reradiation. However, the definition must be specific about the polarization state of the echo that is being considered. As in the case of the RCS definition, there is some disagreement on the form of this convention. We propose the following: that unless otherwise specified LRCS with the symbol $\sigma$ should refer to the echo as received by a polarized detector. In the backscatter case this can be identified with the "copolarized LRCS" where the received polarization is parallel to that transmitted. If both mutually orthogonal polarization states are measured by the detector, then the term "total LRCS" with the symbol $\sigma_{T}$ should be used. For other polarization states, or to avoid 
confusion in any case, the polarization should be made explicit with appropriate indices. With this understanding, and referring to figure 1 , we define the bistatic LRCS as

$$
\sigma_{x y}\left(\theta_{i}, \phi_{i} ; \theta_{r}, \phi_{r}\right)=4 \pi \frac{I_{y}^{r}\left(\theta_{r}, \phi_{r}\right)}{w_{x}^{i}\left(\theta_{i}, \phi_{i}\right)} m^{2}
$$

or equivalently:

$$
\sigma_{x y}\left(\theta_{i}, \phi_{i} ; \theta_{r}, \phi_{r}\right)=4 \pi R^{2} \frac{w_{y}^{r}\left(\theta_{r}, \phi_{r}\right)}{w_{x}^{i}\left(\theta_{i}, \phi_{i}\right)} m^{2} .
$$

This is the same notation used with our definition of BDR and in table I. It is repeated here for convenience:

$I_{Y}^{r}\left(\theta_{r}, \phi_{r}\right)$

$W_{Y}^{r}\left(\theta_{r}, \phi_{r}\right)$

$w_{x}^{i}\left(\theta_{i}, \phi_{i}\right)$

$\mathrm{R}$
Radiant intensity ( $W / S r)$ reflected from target in the direction $\theta_{r} \phi_{r}$ with polarization state $y$.

Radiant flux density $\left(\mathrm{W} / \mathrm{m}^{2}\right)$ at detector entrance pupil reflected from target in the direction $\theta_{r}, \phi_{r}$ with polarization state $y$.

Radiant flux density $\left(\mathrm{W} / \mathrm{m}^{2}\right)$ in laser beam at target from direction $\theta_{i} \phi_{i}$ with polarization state $x$.

Range (m) from target to receiver.

The bistatic LRCS can also be expressed in terms of quantities already defined (see figure 1 ).

$$
I_{Y}^{r}\left(\theta_{r}, \phi_{r}\right)=\int_{\text {surface }} I_{Y}^{r}\left(\theta_{r}, \phi_{r}\right) \cos \theta_{r} d A
$$

where from eq. (1)

$$
L_{y}^{r}\left(\theta_{r}, \phi_{r}\right)=\rho_{x y}^{\prime}\left(\theta_{i}, \phi_{i} ; \theta_{r}, \phi_{r}\right) w_{x}^{i}\left(\theta_{i}, \phi_{i}\right) \cos \theta_{i} \cdot
$$

From eq. (6), the contribution to the LRCS $d \sigma_{x y}\left(\theta_{i}, \phi_{i} ; \theta_{r}, \phi_{r}\right)$ for a uniformly diffusing surface element dA becomes

$$
d \sigma_{x y}\left(\theta_{i}, \phi_{i} ; \theta_{r}, \phi_{r}\right)=4 \pi \rho_{x y}\left(\theta_{i}, \phi_{i} ; \theta_{r}, \phi_{r}\right) \cos \theta_{i} \cos \theta_{r} d A
$$

This result will be used later to derive the LRCS's of various diffuse targets.

The subscripts $x$ and $y$, for laser transmitter and scattered polarizations respectively, ${ }^{1}$ can be specified in a number of ways; for example, $x$

\footnotetext{
${ }^{1}$ This is the usual convention, and consistent with our BDR notation. However, note that Ruck [27] and some others use the left-most index to indicate received polarization and the right-most subscript to indicate transmitter polarization.
} 
and $y$ can refer to the polarization azimuth angle $\alpha$ between the electric field polarization plane and the normal vector to the reference plane [20]. Thus $\alpha=0$ would correspond to perpendicular polarization $\mathrm{x}=1$, and $\alpha=\frac{\pi}{2}$ would correspond to parallel polarization $\mathrm{x}=11$, etc. Another common notation uses the indices $\mathrm{V}$ and $\mathrm{H}$ for vertical and horizontal.

To simplify our further discussion we will henceforth consider only the monostatic LRCS $\left(\theta_{i}=\theta_{r}, \phi_{i}=\phi_{r}\right.$ or $\left.\beta=0\right)$, and azimuthal target symmetry such that the target orientation can be specified by a single aspect angle $\theta$. $\theta$ (2) Copolarized LRCS -- In the monostatic case this is the LRCS for the component whose polarization is parallel to the transmitted polarization. In terms of eq. (6)

$$
\sigma_{x x}(\theta)=4 \pi \frac{I_{x}^{r}(\theta)}{W_{x}^{i}(\theta)} m^{2} .
$$

This is usually abbrievated by $\sigma(\theta)$.

Summary Recommendation: The LRCS $\sigma$ as commonly used without further polarization specification should be identified with the copolarized LRCS, i.e. $\sigma \equiv \sigma_{11}$.

(3) Cross-polarized LRCS -- In the monostatic case, this is the LRCS for the component whose polarization is perpendicular to the transmitted polarization. In terms of eq. (6)

$$
\sigma_{x y}(\theta)=4 \pi \frac{I_{y}^{r}(\theta)}{W_{x}^{i}(\theta)} \quad x \perp y \quad m^{2}
$$

This cross section is usually abbreviated by $\sigma_{\perp}, \sigma_{\mathrm{VH}}$, or $\sigma_{\mathrm{HV}}$. It should be noted that, in general, $\sigma_{x y} \neq \sigma_{y x}$. The cross-polarized LRCS is sometimes referred to as the "depolarized" cross section [77], but this use is discouraged since "depolarized" often refers to scatter containing equal components in the parallel and perpendicular directions [74]. In the latter case the "depolarized LRCS" is equal to $2 \sigma_{\perp}$.

(4) Total LRCS -- The total laser radar cross section represents eq. (6) in the case where $I_{Y^{\prime}}^{r}$ or $W_{Y^{\prime}}^{r}$ includes all the radiant power scattered from the target which is received by the detector. This total consists of the sum of all constituent components. In the literature this division into components has been done in many different ways: in terms of the sum of the two linear polarization states [74], the sum of the polarized and depolarized components $[71,75]$, and the sum of the coherent and incoherent parts [76]. 
It should be clear in the context of the work just what kind of total or summation is referred to. We consider the following form to be the preferred definition:

Total LRCS denoting the sum of both linear reflected polarizations:

$$
\sigma_{x, T}(\theta)=\sigma_{x, x}(\theta)+\sigma_{x, y}(\theta)
$$

This notation is consistent with our BDR definition. Equation (12) is a direct result of eqs. (2) and (6). An obvious abbreviation for $\sigma_{x, T}(\theta)$ is just $\sigma_{T^{*}}$. We feel that this is the most important interpretation of the term "total IRCS." It is also the LRCS, eq. (6), using an unpolarized receiver. For the case where there is coherence between scattered polarization components see references [70] and [71].

The term "total IRCS" is often used in various numerical calculation techniques for LRCS computer codes [71]. These uses do not constitute a definition of a particular LRCS, but the terms are encountered often enough in ladar signature work to justify explanation of their use here. They are:

Total IRCS denoting the sum over the $i$ sub-elements of the target:

$$
\sigma_{T}=\sum_{i} \Delta \sigma_{i}
$$

where $\Delta \sigma_{i}$ is given in eq. (9). The methods for adding the components $\Delta \sigma_{i}$ with the proper phase and scaling factors (for models) constitute one of the most basic and difficult problems in calculating ladar cross sections. We will not comment on these methods here other than to state that the concepts can be quite meaningless for coherent radiation if the phases of the sub-elements are not accounted for correctly.

Total LRCS denoting the sum of the cross section components $\sigma_{\mathrm{n}}$ resolved or divided into n "bins" (see section 3.3.f), and summed over all the "bins."

$$
\sigma_{\mathrm{T}}=\sum_{\mathrm{n}} \sigma_{\mathrm{n}}
$$

The above remarks apply also in this case: It bears repeating that egs. (13) and (14) are calculation techniques, not fundamental definitions.

Summary Conclusion: The appropriate LRCS to denote the case where an unpolarized receiver is used should be referred to as "total LRCS," $\sigma_{\mathrm{T}}$. 
Resolved cross sections are interpreted as the usual LRCS definition applied individually to the ladar return which has been subdivided into various elements of range (range-resolved), frequency (Doppler-resolved), or area elements perpendicular to the range vector (spatially distributed). It should be emphasized that, as discussed here, these terms merely refer to quantities which are convenient for numerical calculation and display and are not distinct in any fundamental sense from the concepts already defined. A formulation for resolved cross sections which has proved to be useful in ladar signature computer simulation is given in the GRC reports $[69,71]$ and will be discussed briefly below.

(1) Range-resolved LRCS -- The range resolved gross section (RRCS) represents the LRCS distributed along the vector line of sight (VLOS). Each one of the $n$ range bins ("resolution elements" or "gate spacing") is of length $c \tau / 2$ where $c$ is the spaed of light and $\tau$ is called the range gate width. This corresponds to the cross-section contribution due to a slice of the target of thickness $c \tau / 2$ which is not masked out by other portions of the target and which is perpendicular to the VLOS. This representation integrates the return signal over finite ranges of delay time so that the cross section is expressed in units of $\mathrm{m}^{2} / \mathrm{m}$.

(2) Doppler-resolved LRCS -- The Doppler-resolved cross section (DRCS) applies to spinning or tumbling targets; the fixed frequency shift due to translation is of no interest in target identification and discrimination. This quantity is defined in a similar way to the RRCS except that the $\mathrm{n}$ range bins are replaced with $\mathrm{n}$ frequency bins. The width of the frequency bins is referred to as the "filter bandwidth" or "filter spacing." The cross section represented by each of the Doppler bins then corresponds to the output of a series of ideal filters each centered at a different frequency. For a target spinning about the symmetry axis of rotation the DRCS is independent of time, while for a tumbling target the DRCS is a function of time. The units are square meters per $\underline{\mathrm{Hz}}$ or $\mathrm{m}^{2} \cdot \mathrm{sec}$.

(3) Distributed LRCS -- The distributed LRCS is sometimes referred to as "angle-resolved" LRCS or LRCS per unit area. The usual symbol for this type of cross section is $\sigma^{\circ}$. It represents the LRCS distributed in both cross range directions perpendicular to the VLOS. The distributed cross section is well defined only for diffuse targets. Distributed cross sections are usually expressed in terms of a cross section per unit area $\left(\mathrm{m}^{2}\right.$ per $\left.\mathrm{m}^{2}\right)$. If this cross section is determined by scanning the target with a laser beam small compared with target dimensions, the measured LRCS values may become a function of the beam parameters [55]. 
Further details, and some of the problems involved in the determination of resolved LRC'S's, are given in reference [71].

\subsection{Differential Scattering Cross Section}

The differential scattering cross section, or simply differential cross section, is used extensively in physics to describe particle scattering $[30,31]$. Only occasionally do these terms appear in a radar or ladar application, e.g. reference [72], where they have a different meaning. The differential cross section (per unit solid angle) $\frac{d \sigma}{d \omega}$, as applied to photons considered as particles, is given by

$$
\frac{\mathrm{d} \sigma}{\mathrm{d} \omega}\left(\theta_{r}, \phi_{r}\right)=\frac{\Gamma_{p}^{r}\left(\theta_{r}, \phi_{r}\right)}{W_{p}^{i}\left(\theta_{i}, \phi_{i}\right)} \frac{m^{2}}{s r}
$$

and has the dimensions of $\mathrm{m}^{2} \cdot \mathrm{sr}{ }^{-1}$. The symbols $\mathrm{I}_{\mathrm{p}}^{\mathrm{r}}\left(\theta_{\mathrm{r}}, \phi_{r}\right)$ for reflected photon intensity, and $w_{p}^{i}\left(\theta_{i}, \phi_{i}\right)$ for incident photon flux density are defined in table 1 . We use the superscript $r$ for "reflected" to be consistent with earlier notation, but "scattered" would be a more appropriate designation here. Note that $\frac{\mathrm{d} \sigma}{\mathrm{d} \omega}$ as defined here differs not only by a factor of $4 \pi$ from the LRCS definitions, but is actually a different concept, being defined in terms of per unit solid angle.

The total cross section in this context [30] denotes an integration over $4 \pi$ steradians about the scattering center. This is also distinctly different from the "total cross section" as defined in section 3.3.e(4).

Summary Recommendation: We discourage both the LR use of "differential cross section" and the use of "total cross section" in the sense of the differential cross section, eq. (15), integrated over the solid angle variable.

\section{THEORETICAL LRCS OF IDEALIZED TARGETS}

In this section we will summarize the LRCS values of some selected standard targets as they have been defined. in section 3.3. These targets are the specular sphere with no absorption, and the perfect Lambertian diffuser. Laboratory standards of a more practical nature are considered in section 5 . 


\subsection{Specular Sphere}

The LRCS of a specular sphere in the far field is the geometric projected area $\sigma=\pi a^{2}$ independent of polarization or bistatic angle $\beta$. Referring to figure 2 , the exact near field case with $\beta=0$ is given by $[36,56]$

$$
\sigma=4 \pi\left(\frac{a R_{1} R_{2}}{a\left(R_{1}+R_{2}\right)+2 R_{1} R_{2}}\right)^{2}
$$

where we have assumed that the radius of curvature of the waves impinging on the target sphere is $R_{2}$. For the case where $R_{1}=R_{2}=R_{\text {, then }}$

$$
\sigma=\pi\left(\frac{a R}{a+R}\right)^{2}
$$

which tends to the far field value $\pi a^{2}$ as $R \rightarrow \infty$, as one would expect. The effect of plane waves on the target can be seen by taking $\mathrm{R}_{2} \rightarrow \infty$. Then

$$
\sigma=4 \pi\left(\frac{a R_{1}}{a+2 R_{1}}\right)^{2}
$$

Which is different from the corresponding case, eq. (17), for incident waves with a radius of curvature $\mathrm{K}_{2}$. The usual practice is to employ incident plane waves even when detectors are in the near field.

By our definition, $\sigma=\sigma_{\mathrm{T}}=\sigma_{\|}$for a perfectly reflecting sphere.

\subsection{Lambertian Diffusers}

As used here, a perfect Lambertian diffuser has the following properties :

1. The absorption is zero. This. implies that $\rho_{\|, T}^{\prime}=\rho_{\perp}^{\prime}, T=\frac{1}{\pi} s^{-1}$ and $\rho_{\|,\|}^{\prime}=\rho_{\perp, 1}=\frac{1}{2 \pi} \operatorname{sr}^{-1}[20]$.

2. The irradiance $\mathrm{E}^{\mathrm{r}}(\theta)$ of the surface varies as $\cos \theta$ and the corresponding radiance $L^{r}$ is independent of $\theta$. This is true no matter how the surface is illuminated.

3. The emitted radiant power is equally divided between mutually orthogonal polarizations also independent of the manner in which the surface is illuminated.

4. The scattered radiation is uncorrelated so that the total power scattered by the target is a simple sum of the power scattered by the constituent subregions.

Several authors have calculated the radiant intensity scattered from simply shaped diffusing targets $[58,59,60]$. These results, along with the definitions and assumptions of section 3.3 .e, give the LRCS values summarized in table II. 


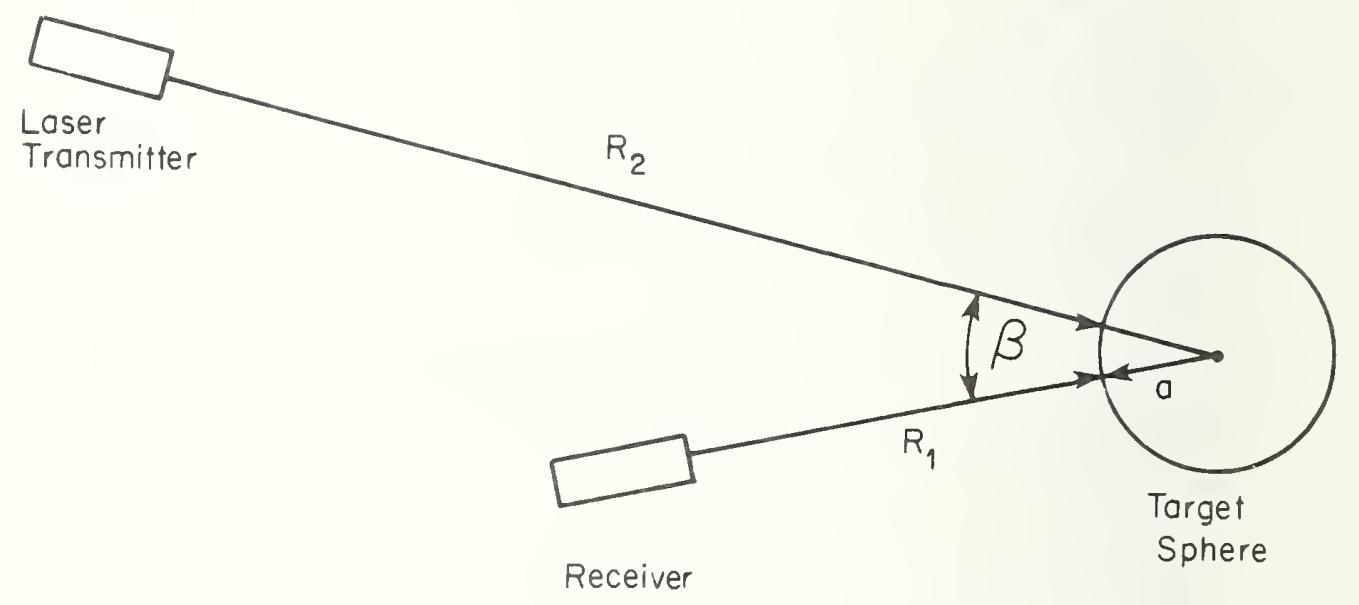

Figure 2. Geometry for sphere LRCS 


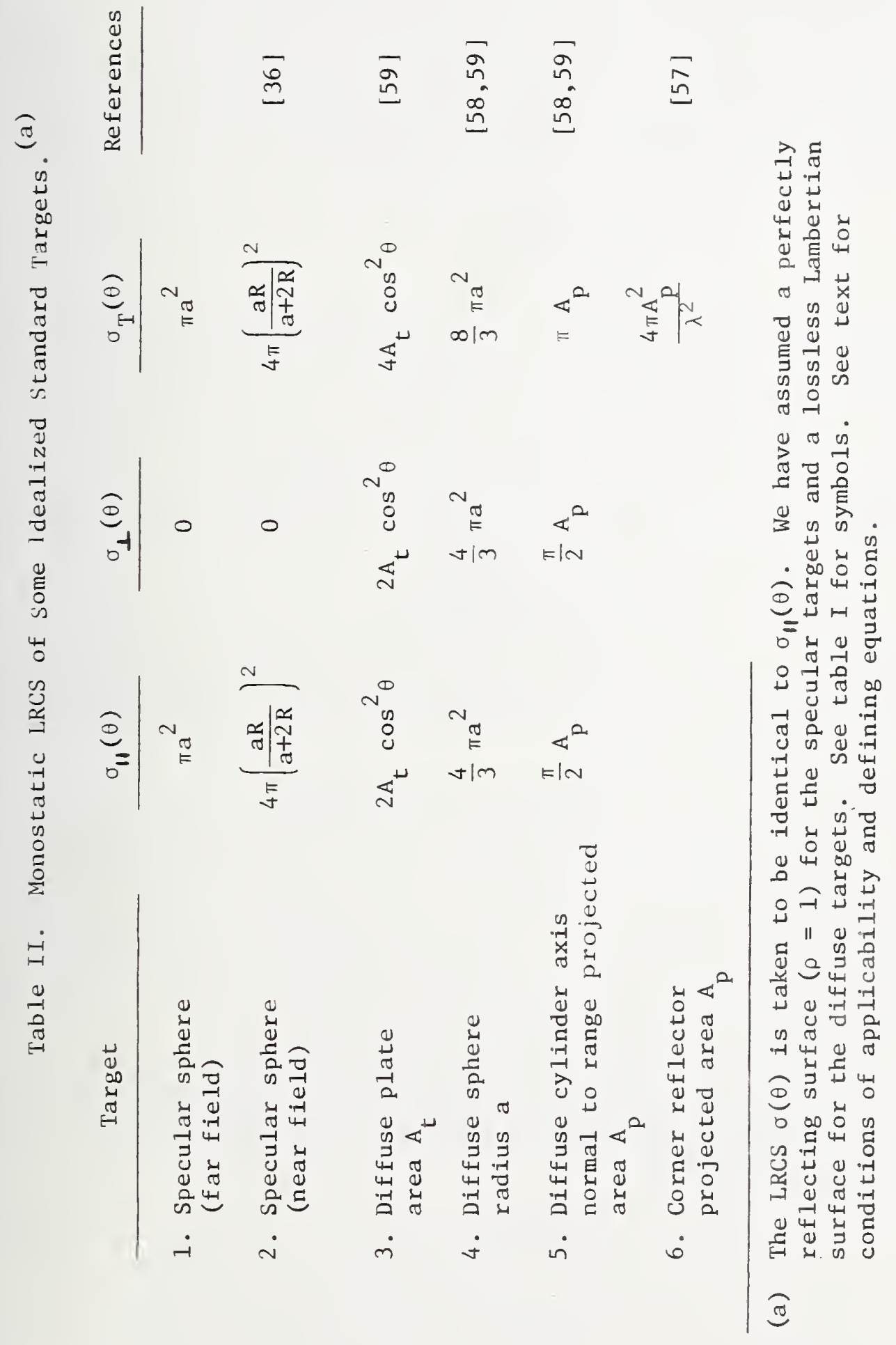




\subsection{Discussion}

The usual approach used for the experimental determination of laser radar cross sections involves the use of calibrated standard targets [32]. The backscattered power from an unknown target $\phi_{\text {tar }}$ is compared with that from a calibration target $\phi_{\mathrm{cal}}$. If the geometry is unchanged while the calibration target is substituted, the unknown target LRCS $\sigma_{\text {tar }}$ is related to the calibration LRCS $\sigma_{\mathrm{Cal}}$ by the simple relation

$$
\frac{\phi_{\text {tar }}}{\phi_{\text {cal }}}=\frac{\sigma_{\text {tar }}}{\sigma_{\text {cal }}}
$$

The value of $\sigma_{\text {cal }}$ can be calculated (section 4) using measured values of reflectivity or BDR. Alternatively $\sigma_{\text {cal }}$ can be determined using the definitions (section 3.2.e) and calibrated power meters.

Radiometric approaches for the calibration of CRCS systems have also been considered [73], but they are difficult to implement.

We will review here some properties of the more commonly used target standards.

\subsection{Specular Targets}

The sphere, or a spherical mirror, has long been used as the standard target in RCS measurements and in many LRCS systems also. Some of the well known properties of the sphere are:

1. In the far field, the scattering is isotropic.

2. For perfect specular reflectivity, there is no depolarization of the incident plane polarized beam.

3. The theoretical cross secticn is not a function of wavelength in the geometrical optics limit. This is largely true in practice also since coatings such as gold have a fairly constant reflectivity over large wavelength intervals in the infrared.

For backscatter measurements it is not necessary to use an entire sphere, since only a small surface area of the sphere participates in the scattering process in the backscatter direction. Referring to figure 3 , the necessary segment $D$ is given by [35]

$$
D>\sqrt{2 \lambda a}
$$

and

$$
\sigma=\rho \pi a^{2}
$$




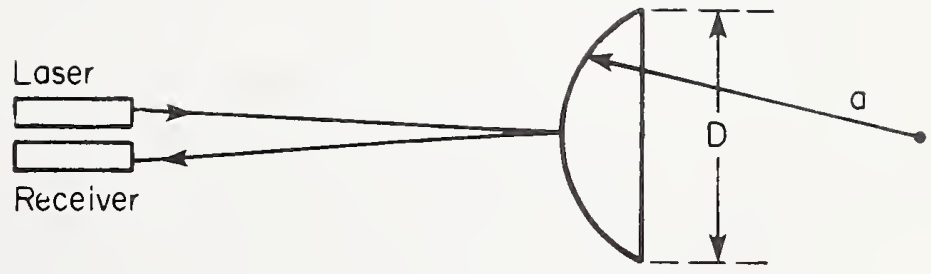

Figure 3. Mirror target dimensions 
independent of $D$ in the limit of $\beta=0$. The required segment size is determined from the condition that at least the first Fresnel zone is included on the surface. Also, care must be taken to avoid backscatter contributions from the edges. Equation (17) implies that only a very small area of the sphere is responsible for the scattering. As an example, for a mirror with a radius of curvature of $r=.1 \mathrm{~m}$ and a wavelength of $\lambda=10.6 \mu \mathrm{m}$, this area is about $1 \mathrm{~mm}^{2}$. The standard target thus "samples" a rather small part of the incident laser beam. If the impinging irradiance is not uniform, as can happen in the near field, variations in measured cross section values will result. Also, imperfections on the mirror, or dust on the surface, can have a similar effect. Statistical averaging of many measurements in different configurations can minimize these problems.

The errors and uncertainties involved in the use of specular spheres or targets have been discussed in the literature. Corrections due to nearfield geometry or a radius of curvature on the impinging beam have been mentioned before [36]. Also, errors due to surface roughness have been discussed $[37,38,39]$. For example, for a sphere whose roughness depth is the order of $10^{-2} \lambda$, the change in RCS is less than . $1 \mathrm{~dB}$. Expected standard deviation of the backscatter as a function of roughness has been treated by Senior [37]. The magnitude of this depolarized component has been reported [34]. In general, experimental LRCS's of a specular sphere or mirror can be very close to the theoretically predicted values.

In conclusion it appears that the important properties of the specular spherical target are sufficiently understood that we may consider it to be a well characterized device suitable for use as a standard target.

\subsection{Diffuse Targets}

Diffuse targets are not as well characterized as the specular sphere. There are many reasons, however, for considering them as standard targets. I'he main reason being that for many years diffuse surfaces have been used as reflectance standards in the visible [41,42] and ir [43,44], and this has given rise to the convention of referencing LRCS values to them [2]. In addition, diffuse standards are essential for Doppler LRCS comparisons, and are convenient for making measurements with diffuse model targets, determining extinction ratios of polarizers, and making cross-polarized LRCS system performance checks.

One characteristic of the backscatter from diffuse targets using conerent radiation is the phenomenon of speckle $[46,45]$. This topic will not be pursued here other than to note that speckle effects must be considered in the interpretation of the backscatter information. We have assumed here that a suitable average has been made over the speckle patterns in all LRCS measurements. 
In the visible region pressed $\mathrm{BaSO}_{4}, \mathrm{MgO}$, and a commercially available white reflectance paint are commonly used as diffuse target scatterers. Ineir properties are well documented [47]. The reflectivity of these surfaces can be quite high, and their scattering properties approach those of an ideal Lambertian diffuser. In the infrared region, particularly around $10.6 \mu \mathrm{m}$, there are no comparably good diffusing surfaces. Sandblasted metal surfaces or gold-plated sandpaper are sometimes used [48]. Scattering from tnis type of diffuser often contains a specular component, or is peaked in tne specular direction. Also, depolarization is usually not complete, cnougn gold-plated sandpaper is fairly good in this respect [49].

\subsection{Retroreflectors}

This type of target is not normally used as a standard, though it may De useful in some applications requiring large backscatter returns. It yields very large values of LRCS the order of $\sigma_{T} \simeq \frac{4 \pi A^{2}}{\lambda^{2}}$ largely independent of aspect angle. $\mathrm{A}$ is the geometrical intercepted area. Its properties are well known [50-54,57].

\subsection{Preferred Standard: Summary Recommendation}

The specular sphere, or spherical mirror, as discussed above appears to offer tne most promise as a preferred standard calibration target, and as a basis for LRCS definitions. It is recommended that this be used as the reference standard for LRCS calibrations. The LRCS of diffuse secondary standards should be experimentally determined according to their backscatter properties relative to the sphere or mirror.

The recommended tolerances, composition (coating), and other specifics of specular standards as well as preferred types of diffuse standards will be discussed in a future report.

\section{CONCLUSIONS}

The main conclusions regarding our preliminary proposals for LR signature standards can be summarized as follows:

1. The fundamental LRCS definitions should be based on, and consistent with, RCS usage.

2. The polarization state of the laser radiation incident on and scattered from the target should be explicitly reported. The LRCS $\sigma$ without further polarization specification should refer to tne copolarized LRCS, i.e. $\sigma \equiv \sigma_{\|}$. 
3. The specular sphere or mirror should be the fundamental calibration standard for laboratory LRCS measurements. The properties of diffuse targets used as secondary standards should be traceable to the specular sphere. 
[1] Hartman, R.L., "Calibration Issues in Laser Radar," U.S. Army Missile Command, Tech. Note RR-76-1 (Oct. 1975).

[2] Wyman, Paul W., "Definition of Laser Radar Cross-Section," Appl. Opt. 7. 207 (1968).

[3] "Metric Practice Guide," ASTM Publication E-380-72 (1972) (Available from ASTM, 1916 Race St., Philadelphia, Pa 19103).

[4] Page, Chester H. and Vigoureux, Paul, "The International System of Units (SI)," Nat. Bur. Stand. (U.S.), Spec. Publ. 330 (1974).

[5] "SI Units and Recommendations for the Use of Their Multiples and of Certain other units," International Organization for standardization Publication ISO-1000-1973(E) (1973) (Available from the American National Standards Institute, 1430 Broadway, New York, N.Y. 10018, Price $\$ 1.50)$.

[6] "NBS Policy for Usage of SI Units," Nat. Bur. Stand. (U.S.), Tech. News Bul1. 57, No. 6, 138-141 (June 1973).

[7] "NBS Guidelines for Use of the Metric System," Nat. Bur. Stand. (U.S.), Circ. LC 1056 (Nov. 1974).

[8] Meyer-Arendt, Jurgen R., "Radiometry and Photometry: Units and Conversion Factors," Appl. Opt. 7, No. 10, 2081-2084 (Oct.'1968).

[9] Nicodemus, Fred E., Ed., Self-Study Manual on Optical Radiation Measurements: Part 1. Concepts. Chapters 1-3," Nat. Bur. Stand. (U.S.), Tech. Note 910-1 (March 1976).

[10] Judd, Deane B., "Terms, Definitions, and Symbols in Reflectometry," J. Opt. Soc. Amer. 57, No. 4, 445-452 (April 1967).

[11] Venable, William H. and Hsia, Jack J., "Optical Radiation Measurements: Describing spectrophotometric Measurements," Nat. Bur. Stand. (U.S.), Tech. Note 594-9 (Nov. 1974).

[12] Geist, Jan and Zalewski, Edward, "Chinese Restaurant Nomenclature for Radiometry," Appl. Opt. 12, No. 2, 435-436 (Feb. 1973).

[13] Nicodemus, Fred. E., "Comments on: Chinese Restaurant Nomenclature for Radicmetry," Appl. Opt. 12, No. 4, 904-906 (April 1973).

[14] Nicodemus, Fred E., "Reflectance Nomenclature and Directional Reflectance and Emissivity," Appl. Opt. 9, No. 6, 1474-1475 (June 1970).

[15] Nicodemus, Fred E., "Directional Reflectance and Emissivity of an Opaque Surface," Appl. Opt. $\underline{4}$, No. 7, 767-773 (July 1965).

[16] Spencer, Domina Eberle and Gastor, Eugene A., "Current Definitions of Reflectance," J. Opt. Soc. Amer. 65, No. 10, 1129-1132 (Oct. 1975).

[17] Nicodemus, Fred E., "Comment on Current Definitions of Reflectance," J. Opt. Soc. Amer. 66, No. 3, 283-285 (March 1976). 
[18] Born, Max and Wolf, Emil, "Principals of Optics," Second Edition, p. 182 (footnote) (MacMillan Co., New York, N.Y., 1964).

[19] Nicodemus, Fred E., "Military Standards: Infrared Terms and Definitions. Part 1," NTIS Report AD 758341 (Dec. 1971).

[20] Maxwell, J.R., "Target Signature Analysis Center: Data Compilation, Eleventh Supplement. Bidirectional Reflectance: Definition, Discussion, and Utilization," Willow Run Laboratories Report AFAL-TR-72-226, I (Oct. 1972).

[21] Kerr, Donald E., Ed., "Propagation of Short Radio Waves," Vol. 13, Radiation Laboratory Series, pp. 33 \& 468 (McGraw-Hill Book Co., Inc., New York, N.Y., 1951).

[22] Blacksmith, P., Hiatt, R.E., and Mack, R.B., "Introduction to Radar Cross-Section Measurements," Proc. IEEE 53, No. 8, 903 (Aug. 1965).

[23] Skolnik, Merrill I., "Introduction to Radar Systems," p. 40 (McGrawHill Book Co., Inc., New York, N.Y., 1962).

[24] Schiff, Leonard I., "Quantum Mechanics," Second Edition, p. 111 (MCGraw-Hill Book Co., Inc., New York, N.Y., 1955).

[25] Reference [18], p. 659.

[26] Morse, Philip M. and Feshbach, Herman, "Methods of Theoretical Physics," Vol. 2, p. 1485 (McGraw-Hill Book Co., Inc., New York, New York, 1953).

[27] Ruck, George T., Ed., "Radar Cross Section Handbook," pp. 17-21 (Plenum Press, New York, N.Y., 1970).

[28] Reference [22], p. 904.

[29] Reference [27], p. 893.

[30] Reference [24], p. 97.

[31] Merzbacher, Eugene, "Quantum Mechanics," p. 215 (John Wiley \& Sons, Inc., New York, N.Y., 1961).

[32] Krichbaum, C.K., "Radar Cross-section Measurements," Radar Cross Section Handbook, Vol. 2, Chapter 11, 893-935 (George T. Ruck, Ed., Plenum Press, New York, N.Y., 1970).

[33] Michels, James H., Bromley, Eugene E., and Demma, Fred J., "Laser Radar Signatures of RV Models of Interest in Ballistıc Missile Defense," Rome Air Development Center in House Report RADC-TR-75-319, 10, 11 (Feb. 1976).

[34] Reference [33], p. 13.

[3b] Ridenouir, Louis E., Ed., "Radar system Engineering," MIT Radiation Laboratory Series, Vol. I, p. 66 (McGraw-Hill Book Co., Inc., New York, New York, 1947).

[36] Senior, T.B.A. and Kiegel, K.M., "A Theory of Radar scattering by the Moon," J. Res. Nat. Bur. Stand. (U.S.), 64D, No. 3, 225 (May-June 1960). 
[37] Senior, T.B.A., "Surface Roughness and Tolerances in Model Scattering Experiments, IEEE Trans. on Antennas \& Propagation, AP-13, 629-636 (July 1965).

[38] Hiatt, R.E., Senior, T.B.A., and Weston, V.H., "A Study of surface Roughness and its Effect on the Backscattering Cross Section of Spheres," Proc. IRE 48, 2008 (1960).

[39] Burrows, M.L., "Radar Echo Variations of a Large Rough Sphere," IEEE Trans. On Antennas \& Propagation AP-14, No. 4, 455-460 (July 1966).

[40] Malick, J.D., Naar, J., Nephew, W.A., and Peppers, N.A., "Implications of Evolving Laser Technology. Phase II: Observables and Discriminants," (U), Samso Report No. TR 71-220, Stanford Research Institute, secret (July 1971).

[41] Erb, J., "Requirements for Reflection Standards and the Measurement of Their Reflection Waves," Appl. Opt. 14, No. 2, 493-499 (Feb. 1975).

[42] Budde, Wolfgang, "Standaris of Reflectance," J. Opt. Soc. Amer. 50, No. 3, 217-220 (March 1960).

[43] Trytten, Grover and Flowers, Wayne, "Optical Characteristics of a Proposed Reflectance Standard," Appl. Opt. 5, No. 12, 1895-1897 (Dec. 1966).

[44] Agnew, John T. and McQuistan, Richmond B., "Experiments Concerning Infrared Diffuse Reflectance Standards in the Range . 8 to 20 Microns," J. Opt. Soc. Amer. 43, No. 11, 999-1007 (Nov. 1953).

[45] George, Nicholas, "Speckle," Optics News 2, No. 1, 14-20 (Jan. 1976).

[46] Dainty, J.C., Ed., "Laser Speckle and Related Phenomena," Topics in Applied Physics, Vol. 9 (Springer-Verlag, New York, N.Y., 1975).

[47] Grum, F. and Luckey, G.W., "Optical Sphere Paint and a Working Standard of Reflectance," Appl. Opt. I, No. 11, 2289-2294 (Nov. 1968).

[48] Cuneo, M.A. and Zakrzewski, T.M., "Survey of Laser Signature Measurements and Prediction Models," General Research Corp. Report 566W-02-CR (April 1975).

[49] Holl, Herbert B., MICOM, private communication.

[50] Robertson, S.D., "Targets for Microwave Radar Navigation," Bell syst. Tech. J. 26, 852-869 (Oct. 1947).

[51] Peck, E.R., "Theory of the Corner Cube Interferometer," J. Opt. Soc. Amer. 38, 1015-1024 (Dec. 1948).

[52] Spencer, R.C., "Corner Cube Reflectors," Radar Aids to Navigation, (J.S. Hall, Ed., McGraw-Hill Book Co., Inc., New York, N.Y., 1947).

[53] Chandler, K.N., "Effect of Small Errors on the Angles of Corner Cube Reflectors," J. Opt. Soc. Amer. 50, 203-206 (March 1960). 
[54] Yoder, P.R., Jr., "Study of Light Deviation Errors in Triple Mirrors and Tetrahedral Mirrors," J. Opt. Soc. Amer. 48, 496-499 (JuLy 1958).

[55] Wyman, P.W., "Laser Radar Range Considerations," NRL Report AD 699519 (Dec. 1969).

[56] Weston, V.H., "Exact Near Field and Far Field Solution for the Backscattering of a Pulse from a Perfectly Conducting sphere. Univ. of Michigan Lab. Rept. No. 2778-4-T (1959).

[57] Reference [35], p. 67.

[58] Look, D.C., Ir., "General Expression for Lambert Diffuse Reflection," J. Opt. Soc. Amer. 55, 462 (1965).

[59] Rambauske, Werner R. and Gruenzel, Ronald R., "Distribution of Diffuse Optical Reflection Around Some Stereometric Surfaces," J. Opt. Soc. Amer. 55, No. 3, 315-318 (March 1965).

[60] Sussman, M., "Note on Perfect Lambertian Diffusers," J. Opt. Soc. Amer. $48,275-276$ (April 1958).

[61] "American Standard Nomenclature for Radiometry and Photometry," ASA 258.1.1-1953, American Standaras Association, Inc. (Feb. 27, 1953). Now superseded by References [62] and [63].

[62] "American National Standard Nomenclature and Definitions for Illuminating Engineering," ANSI 27.1-1967 (Revision of 27.1-1942), RP-16, Approved by American National standards Institute, Sponsored and Published by Illuminating Engineering Society, 345 East 47 th Street, New York, N.Y. 10017.

[63] "American National Standard Letter Symbols for Units Used in Science and Technology," ANSI Y10.19-1969 (Revision of USAS Y10.19-1967) (IEEE No. 260), approved by American National Standards Institute and Adopted for Mandatory Use by the Department of Defense on December 10, 1969, Sponsored and Published by the American Society of Mechanical Engineers, United Engineering Center, 345 East 47 th Street, New York, N.Y. 10017.

[64] "International Lighting Vocabulary," 3rd Edition, Common to the CIE and IEC (International Electrotechnical Commission), Interrational Commission on Illumination (CIE), Bureau Central de la CIE, 4 Av. du Recteur Poincaré, 75-Paris 16 ${ }^{e}$, France, Publication CIE No. 17 (E-1.1) (1970).

[65] Clark, Jones R., "Terminology in Photometry and Radiometry," J. Opt. Soc. Amer. 53, No. 11, 1314-1315 (Nov. 1963).

[66] Spiro, I.J., Jones, R. Clark, and Wark, D.Q., "Atmospheric Transmission Concepts, Symbols, Units, and Nomenclature," Infrared Physics $\underline{5}$, No. 1, 11-36 (March 1965). 
[67] Gilbert, John, "Review of Optical Predictive Reflectance Models," General Research Corporation Report WGRC 75-3916 (March 1975).

[68] Mauck, J.D., Naar, J., Nephew, W.A., and Peppers, N.A., "Implications of Evolving Laser Technology, " "Phase II. Observables and Discriminants," (U) Samso Technical Report, No. 71-220, Secret (July 1971).

[69] Gilbert, J.L., Kramer, P.J., Radley, R.J., and Wilson, J., "Laser Signature Handbook," (U), Vol. 1, "Total and Resolved Cross Sections," (U), General Research Corporation Report, WGRC 75-4014, Secret (Sept. 1975).

[70] Leader, J.C., "Investigation of Laser Radar Cross Section Analysis," Report MDC A2990, MCDonnell Douglas Corporation (Aug. 1974).

[71] "BMD Laser Signature Modeling Program," (U), Final Technical Report 566W-08-CR, General Research Corporation, Secret (Jan. 1976).

[72] Reference [27], p. 893.

[73] Spinak, Sidney, MDAC, private communication.

[74] Cheo, P.K. and Renau, J., "Wavelength Dependence of Total and Depolarized Back-Scattered Laser Light from Rough Metallic Surfaces," J. Opt. Soc. Amer. 59, No. 7, 823 (July 1969).

[75] Renau, J., Cheo, P.K., and Cooper, H.G., "Depolarization of Linearly Polarized EM Waves Backscattered from Rough Metals and Inhomogeneous Dielectrics," J. Opt. Soc. Amer. 57, No. 4, 461 (April 1967).

[76] Boyd, M.L. and Deavenport, R.L., "Forward and Specular Scattering from a Rough Surface: Theory and Experiment," J.Acous. Soc. Amer. 53, No. 3, 794 (1973).

[77] Leader, J.C. and W.A.J. Dalton, "Bidirectional Scattering of Electromagnetic Waves from the Volume of Dielectric Materials," J. Appl. Phys. 43, No. 7, 3086 (July 1972).

[78] Spiro, Irving J., "Radiometry and Photometry," Opt. Engineering 13 , No. 5, G183 (Sept./Oct. 1974).

[79] Spiro, Irving J., "Radiometry and Photometry," Opt. Engineering 15 . No. 1, SR-7 (Jan./Feb. 1976). 
8. APPENDIX. RADIOMETRIC SYSTEMS

The three principal nomenclature systems for radiometry and photometry are compared in the following three tables. This information has been taken from the report by Nicodemus [19] on proposed military standard infrared terms and definitions. The present report follows the nomenclature given in table A-II. 
Table A-1. Former American Standard Nomenclature for Radiometry and Photometry.

[taken from ASA 258.1.1-1953] [60]
$\underline{\text { Terms }}$
Symbols
Units
$1 \quad$ Flux

$\begin{array}{ll}-- & {[\Phi] \text { flux }} \\ P & {[\mathrm{~W}] \text { watts }} \\ \text { F } & {[1 \mathrm{~m}] \text { lumens }} \\ -- & {\left[\mathrm{q} \cdot \mathrm{s}^{-1}\right] \text { quanta per second }} \\ -- & {\left[\Phi \mathrm{sr}^{-1}\right]} \\ J & {\left[\mathrm{~W} \mathrm{sr}^{-1}\right]} \\ \text { I } & {[1 \mathrm{~m} \mathrm{sr}-1]} \\ -- & {\left[\mathrm{q} \cdot \mathrm{s}^{-1} \cdot \mathrm{sr}^{-1}\right]} \\ \text { W,H,L, or E } & {\left[\Phi \cdot \mathrm{cm}^{-2}\right]}\end{array}$
3
1(a) Radiant flux
I(b) Luminous flux
(Photon flux)
1 (c)
(Intensity)
2(a) Radiant intensity
2(b) Luminous intensity
2(c) (Photon intensity)
3 [radiant or luminous ]
$\mathrm{W}, \mathrm{H}, \mathrm{L}$, or $\mathrm{E} \quad\left[\Phi \cdot \mathrm{cm}^{-2}\right]$
3.1
flux density
3.1 (a) Radiant emittance
3.1 (b) Luminous emittance

$\begin{array}{ll}-- & {\left[\Phi \cdot \mathrm{cm}^{-2}\right]} \\ W & {\left[\mathrm{~W} \cdot \mathrm{cm}^{-2}\right]}\end{array}$
3.1(c) (Photon emittance)
L
3.2
3.2 (a) Irradiance

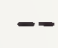
$\left[\mathrm{q} \cdot \mathrm{s}^{-1} \cdot \mathrm{cm}^{-2}\right]$
$\left[\Phi \cdot \mathrm{cm}^{-2}\right]$
$\mathrm{H}$
$\left[\mathrm{W} \cdot \mathrm{cm}^{-2}\right]$
3.2 (b) Illuminance or Illumination
E
$\left[1 \mathrm{~m} \cdot \mathrm{cm}^{-2}\right]$
3.2 (c) - - - -
$\left[\mathrm{q} \cdot \mathrm{s}^{-1} \cdot \mathrm{cm}^{-2}\right]$
4
4 (a) Radiance
$\mathrm{N}$
$\left[\Phi \cdot \mathrm{cm}^{-2} \cdot \mathrm{sr}^{-1}\right.$ ]
$\left[\mathrm{W} \cdot \mathrm{cm}^{-2} \cdot \mathrm{sr}^{-1}\right.$ ]
4 (b) Luminance
[photometric brightness]
B
$\left[1 \mathrm{~m} \cdot \mathrm{cm}^{-2} \cdot \mathrm{sr}^{-1}\right]$
$4(\mathrm{c})$
- - - -
$\left[\mathrm{q} \cdot \mathrm{s}^{-1} \cdot \mathrm{cm}^{-2} \cdot \mathrm{sr}^{-1}\right]$

NOTE 1. Terms and symbols in parentheses are not given in the cited source but are simple logical extensions of that material. Dashes represent missing terms or symbols for which no such simple logical extension is available.

NOTE 2. Although superseded, these terms and symbols are still used by many in the U.S.A. and will be found in most standard texts and in a large majority of the reports in the files of NTIS (National Technical Information Service). 
Table A-II. American National Standard Nomenclature Illuminating Engineering •

[taken from ANSI Z7.1-1967 (RP-16)] [62]

Terms

1

1(a) Radiant flux

1(b) Luminous flux

1fc) (Photon flux)

2

2 (a)

2 (b)

2 (c)

3

3.1

3.1 (a) Radiant exitance

3.1(b) Luminous exitance

3.1(c) (Photon exitance)

3.2

3.2 (a) Irradiance

3.2(b) Illumination [I1luminance]

$3.2(c) \quad-\cdots$

4

4 (a) Radiance

4 (b) Luminance

4 (c)

Intensity

Radiant intensity

Luminous intensity

(Photon intensity)

Flux density at a surface

Exitance
Terms

Flux
Symbols Units

$\begin{array}{ll}\Phi & {[\Phi] \text { flux }} \\ \Phi_{\mathrm{e}} & {[\mathrm{W}] \text { watts }} \\ \Phi_{\mathrm{v}} & {[1 \mathrm{~m}] \text { lumens }}\end{array}$

$\left(\Phi_{p}\right)$

I

$I_{\mathrm{e}}$

$\mathrm{I}_{\mathrm{V}}$

$\left(I_{p}\right)$

$M_{\mathrm{e}}^{--}$
$\mathrm{M}_{\mathrm{v}}$
$\left(\mathrm{M}_{\mathrm{p}}\right)$

E

E

$\mathrm{E}_{\mathrm{v}}$

$\left(E_{\mathrm{P}}\right)$

$\mathrm{L}$

$\mathrm{L}_{\mathrm{e}}$

$\mathrm{L}_{\mathrm{v}}$

$\left(\mathrm{L}_{\mathrm{p}}\right)$ $\left[q \cdot s^{-1}\right]$ quanta per second $\left[\Phi \cdot \mathrm{sr}^{-1}\right]$

$\left[\mathrm{W} \cdot \mathrm{sr}^{-1}\right]$

$\left[1 \mathrm{~m} \cdot \mathrm{sr}^{-1}\right.$ ]

$\left[\mathrm{q} \cdot \mathrm{s}^{-1} \cdot \mathrm{sr}^{-1}\right]$

$\left[\Phi \cdot \mathrm{cm}^{-2}\right]$

$\left[\Phi \cdot \mathrm{cm}^{-2}\right]$

$\left[\mathrm{W} \cdot \mathrm{cm}^{-2}\right]$

$\left[1 \mathrm{~m} \cdot \mathrm{cm}^{-2}\right]$

$\left[\mathrm{q} \cdot \mathrm{s}^{-1} \cdot \mathrm{cm}^{-2}\right]$

$\left[\Phi \cdot \mathrm{cm}^{-2}\right]$

$\left[\mathrm{W} \cdot \mathrm{cm}^{-2}\right]$

$\left[1 \mathrm{~m} \cdot \mathrm{cm}^{-2}\right]$

$\left[\mathrm{q} \cdot \mathrm{s}^{-1} \cdot \mathrm{cm}^{-2}\right]$

$\left[\Phi \cdot \mathrm{cm}^{-2} \cdot \mathrm{sr}^{-1}\right]$

$\left[\mathrm{W} \cdot \mathrm{cm}^{-2} \cdot \mathrm{sr}^{-1}\right]$

$\left[1 \mathrm{~m} \cdot \mathrm{cm}^{-2} \cdot \mathrm{sr}^{-1}\right]$

$\left[\mathrm{q} \cdot \mathrm{s}^{-1} \cdot \mathrm{cm}^{-2} \cdot \mathrm{sr}^{-1}\right]$

NOTE 1. Terms and symbols in parentheses are not given in the cited source, but are simple logical extensions of that material. Dashes represent missing terms or symbols for which no such simple logical extension is available.

NOTE 2. These terms and symbols are essentially the same as those adopted internationally [CIE [64]] and have been adopted by Applied Optics, the Journal of the Optical Society of America, and the Proceedings of IRIS and by the National Bureau of Standards, as we11 as the Illuminating Engineering Society and its Journal. 
Table A-III. Proposed Terms and Symbols for Radiometry (Including Photometry).

[based on the PHLUOMETRY scheme of R. Clark Jones] $[65,66$ ]

Terms

$1 \quad$ Flux

I(a) Radiant flux

I (b) Luminous flux

I(c) Photon flux

2 Intensity

2(a) Radiant intensity

2 (b) Luminous intensity

2(c) Photon intensity

3 Flux density at a surface

3.1 Exitance

3.I(a) Radiant exitance

3.I(b) Luminous exitance

3.1(c) Photon exitance

3.2 Incidance

3.2 (a) Radiant incidance (irradiance)

3.2(b) Luminous incidance (illuminance)

3.2(c) Photon incidance

4

4 (a) Radiant sterance (radiance)

4 (b) Luminous sterance (luminance)

4(c) Photon sterance

\section{Symbols Units}

$\Phi$

$\Phi_{\mathrm{e}}$

[థ] flux

[W] watts

[1m] lumens

$\left[\mathrm{q} \cdot \mathrm{s}^{-1}\right]$ quanta per second $\left[\Phi \cdot \mathrm{sr}^{-1}\right]$

$\left[\mathrm{W} \cdot \mathrm{sr}^{-1}\right]$

$\left[1 \mathrm{~m} \cdot \mathrm{sr}^{-1}\right]$

$\left[\mathrm{q} \cdot \mathrm{s}^{-1} \cdot \mathrm{sr}^{-1}\right]$

$\left[\Phi \cdot \mathrm{cm}^{-2}\right]$

$\left[\Phi \cdot \mathrm{cm}^{-2}\right]$

$\left[\mathrm{W} \cdot \mathrm{cm}^{-2}\right]$

$\left[1 \mathrm{~m} \cdot \mathrm{cm}^{-2}\right]$

$\left[\mathrm{q} \cdot \mathrm{s}^{-1} \cdot \mathrm{cm}^{-2}\right]$

$\left[\Phi \cdot \mathrm{cm}^{-2}\right]$

$\left[\mathrm{W} \cdot \mathrm{cm}^{-2}\right.$ ]

$\left[1 \mathrm{~m} \cdot \mathrm{cm}^{-2}\right]$

$\left[\mathrm{q} \cdot \mathrm{s}^{-1} \cdot \mathrm{cm}^{-2}\right]$

$\left[\Phi \cdot \mathrm{cm}^{-2} \cdot \mathrm{sr}^{-1}\right]$

$\left[\mathrm{W} \cdot \mathrm{cm}^{-2} \cdot \mathrm{sr}^{-1}\right]$

$\left[\mathrm{Im} \cdot \mathrm{cm}^{-2} \cdot \mathrm{sr}^{-1}\right]$

$\left[\mathrm{q}^{\circ} \mathrm{s}^{-1} \cdot \mathrm{cm}^{-2} \cdot \mathrm{sr}^{-1}\right]$

NOTE: Also see references [78,79] for further additions. 
NBS.114A \{REV. 7-73)

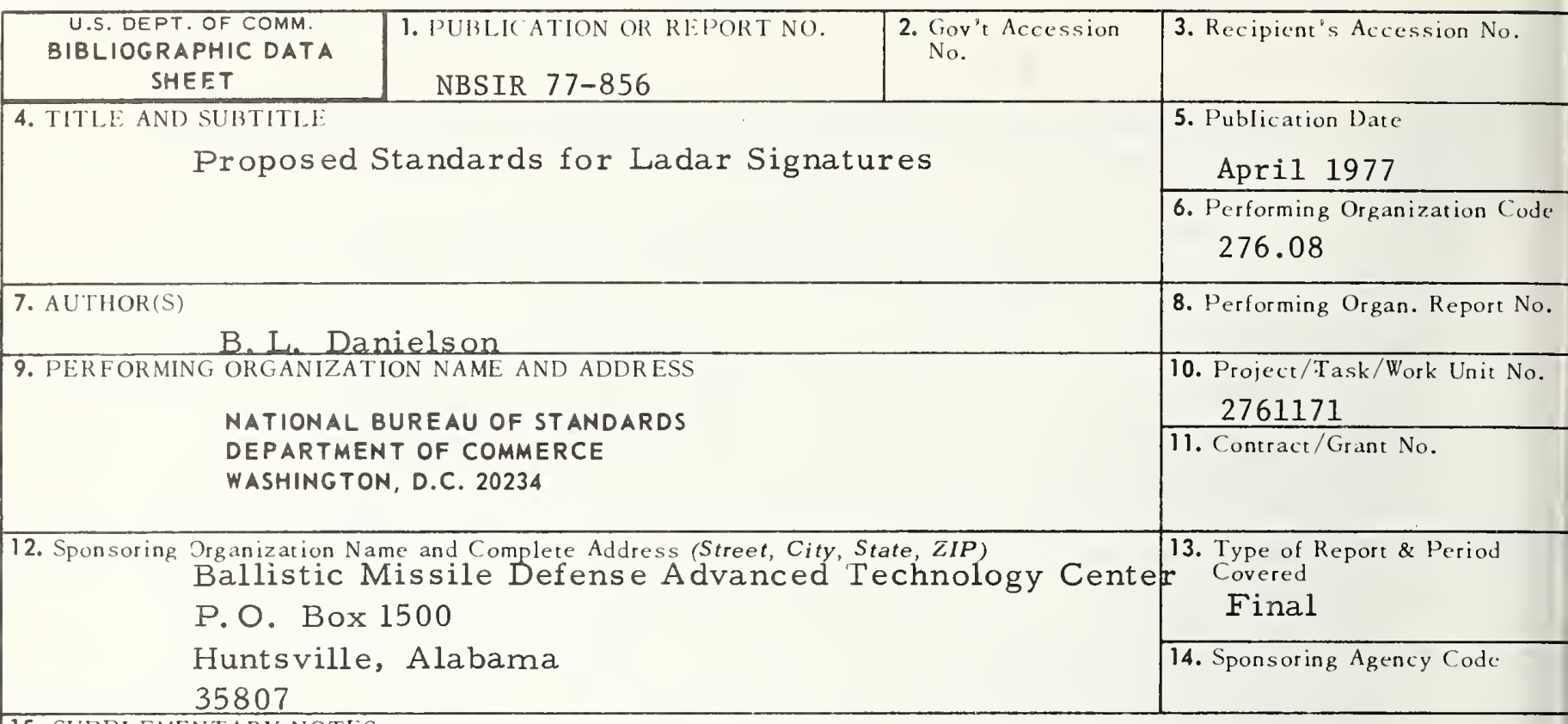

15. SUPPIEMENTARY NOTES

16. ABSTRACT (A 200-word or less factual summary of most significant information. If document includes a significant bibliography or literature survey, mention it here.)

This report attempts to assist in providing a common basis for the reporting and intercomparison of laser radar cross section (LRCS) data generated at different laboratories for the Ballistic Missile Defense Advanced Technology Center (BMDATC) laser radar signatures program. We are concerned here with recommending preferred definitions of some of the most commonly used LRCS terms and recommending a calibration target standard.

17. KEY WORDS (six to twelve entries; alphabetical order; capitalize only the first letter of the first key word unless a proper name; separated by semicolons)

Laser radar; laser radar signatures; target standards

18. AVAILABILITY X Unlimited

For Official Distribution. Do Not Release to NTIS

Order From Sup. of Doc., U.S. Government Printing Office

Washington, D.C. 20402, SD Cat. No. C13

X Order From National Technical Information Service (NTIS) Springfield, Virginia 22151

\begin{tabular}{|l|c|}
\hline $\begin{array}{l}\text { 19. SECURITY CLASS } \\
\text { (THIS REPURT) } \\
\text { UNCLASSIFIED }\end{array}$ & 21. NO. OF PAGES \\
\hline $\begin{array}{l}\text { 20. SECURITY CLASS } \\
\text { (THIS PAGE) }\end{array}$ & $\begin{array}{l}\text { 22. Price } \\
\text { UNCLASSIFIED }\end{array}$ \\
\hline
\end{tabular}

